
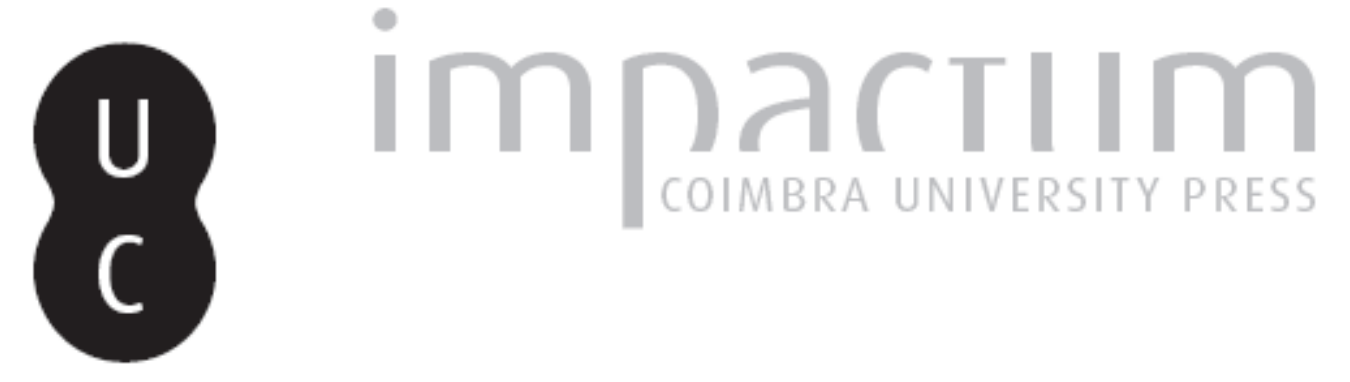

\title{
Tutela coletiva específica ou resultado prático equivalente: a indenização moral coletiva revertida para a própria comunidade lesada
}

\author{
Autor(es): $\quad$ Rapassi, Rinaldo Guedes \\ Publicado por: Imprensa da Universidade de Coimbra \\ URL \\ persistente: \\ URI:http://hdl.handle.net/10316.2/33229 \\ DOI: \\ DOI:http://dx.doi.org/10.14195/1647-8630_24_9
}

Accessed : $\quad$ 26-Apr-2023 11:04:41

A navegação consulta e descarregamento dos títulos inseridos nas Bibliotecas Digitais UC Digitalis, UC Pombalina e UC Impactum, pressupõem a aceitação plena e sem reservas dos Termos e Condições de Uso destas Bibliotecas Digitais, disponíveis em https://digitalis.uc.pt/pt-pt/termos.

Conforme exposto nos referidos Termos e Condições de Uso, o descarregamento de títulos de acesso restrito requer uma licença válida de autorização devendo o utilizador aceder ao(s) documento(s) a partir de um endereço de IP da instituição detentora da supramencionada licença.

Ao utilizador é apenas permitido o descarregamento para uso pessoal, pelo que o emprego do(s) título(s) descarregado(s) para outro fim, designadamente comercial, carece de autorização do respetivo autor ou editor da obra.

Na medida em que todas as obras da UC Digitalis se encontram protegidas pelo Código do Direito de Autor e Direitos Conexos e demais legislação aplicável, toda a cópia, parcial ou total, deste documento, nos casos em que é legalmente admitida, deverá conter ou fazer-se acompanhar por este aviso.

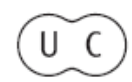


RE VISTA P O R T U G U E S A
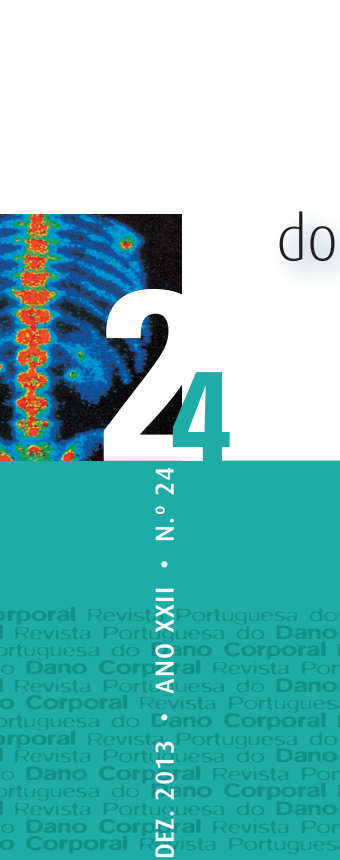

$$
\text { RE VISTA P OR TU/G U E S A }
$$

do

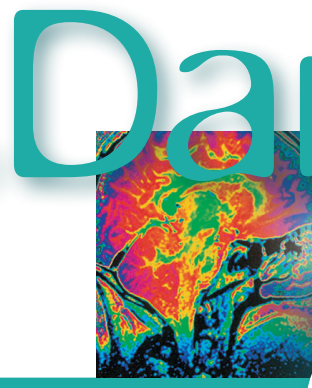

ন

$\stackrel{\circ}{\dot{z}}$

$\dot{\bar{x}}$

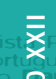

Ono Corporal Revistaral Revista Portuming

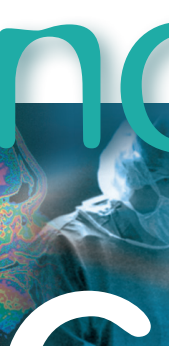

(9)

12

tै. strentes

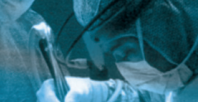

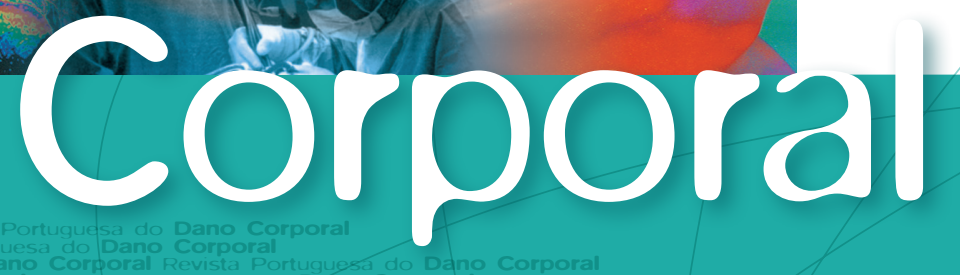

-

m Portuguesa do Dano Corporal Revista Portuguesa do Qano Corporal

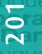
ristal

Corporal Revista Portuquesa do Dano Corpograi Revista Portuquesa do Dang Corporal

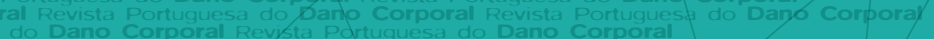

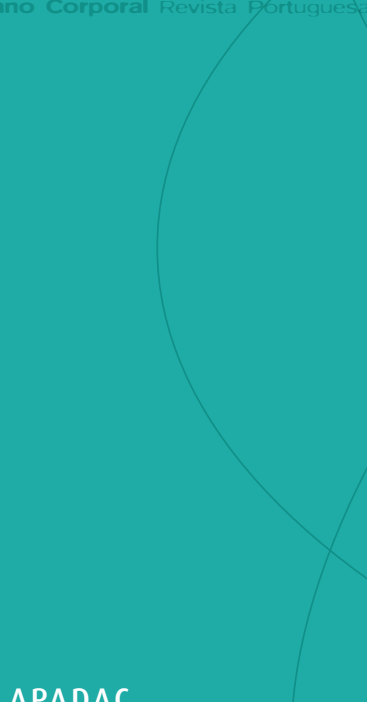

APADAC

ASSOCIAÇÃO PORTUGUESA

DE AVALIAÇÃO

DO DANO CORPORAL

FACULDADE DE MEDICINA

DA UNIVERSIDADE

DE COIMBRA 


\section{Tutela coletiva específica ou resultado prático equivalente: a indenização moral coletiva revertida para a própria comunidade lesada}

Rinaldo Guedes Rapassi ${ }^{1}$

\section{Introdução}

No vasto território brasileiro, constata-se grande dificuldade de acesso à saúde de qualidade, à educação profícua e à segurança eficiente.

Por que isso acontece?

Há quem dê justificativa histórica para nossos problemas, é verdade.

Contudo, JOSUÉ DE CASTRO define com propriedade que "o subdesenvolvimento é o produto da má utilização dos recursos naturais e humanos realizada de forma a não conduzir à expansão econômica e a impedir as mudanças sociais indispensáveis ao processo da integração dos grupos humanos subdesenvolvidos dentro de um sistema econômico integrado" (sem destaque no original) .

Certamente, há espaço para que o Estado brasileiro seja mais eficiente em utilizar melhor os recursos naturais e humanos à sua disposição e, assim, promover o desenvolvimento com maior eficiência.

\footnotetext{
1 Juiz do Trabalho Substituto junto ao Tribunal Regional do Trabalho da $5^{\text {a }}$ Região. Especializado em Direito Material e Processual do Trabalho e habilitado em Didática do Ensino Superior, ambos pela Universidade Presbiteriana Mackenzie - Brasília. Especializado em Direito do Consumidor, Processos Coletivos e Direito Ambiental pela Escola Superior de Advocacia da Ordem dos Advogados do Brasil - Secção São Paulo. Bacharel em Direito, com habilitação em Direito do Trabalho e da Segurança Social, pela Faculdade de Direito da Universidade de São Paulo - USP
} 


\section{0 papel do judiciário}

Visando a cumprir integralmente seu papel, o Estado não deve se limitar à punição dos infratores, sem tentar adotar estratégias de prevenção e de orientação ou assegurar a preservação das vítimas. Em outras palavras, deve ter em vista também a solução do problema, além da punição ao infrator.

Para tanto, o Estado precisa de instituições fortes, que atuem de foram articulada sem perder de vista direitos humanos, como diagnosticou recentemente o sociólogo RENATO SÉRGIO DE LIMA. Mas, "o modelo é esquizofrênico. Muitas vezes as polícias, o Ministério Público e o Judiciário trabalham em oposição uns aos outros".

Nesse contexto, a responsabilidade pelo desenvolvimento socioeconômico não é só do Poder Executivo, ou do Legislativo. É do Estado como um todo e, pois, também do Poder Judiciário, além de parcela que cabe à própria sociedade (e das empresas nela inseridas).

Atentemos que o Juiz é um agente político - não precisa pedir autorização a quem quer que seja para finalizar o dispositivo de sua sentença com as respostas às seguintes questões de uma ação civil pública: quanto, onde, quando e como reparar efetivamente o dano que aquela comunidade sofreu?

E o Juiz do Trabalho, pelo grande número de audiências que preside diariamente, é um agente político que tem especial conhecimento dos problemas sociais brasileiros. Por isso, pode e deve fazer uso de seu poder constitucional, da forma mais ampla que estiver ao seu alcance, a fim de fomentar o desenvolvimento e de forma a suprir algumas carências sociais importantes.

Em outras palavras, é dever primeiro do magistrado procurar atender às metas institucionais tradicionais. Mas, além disso, não há de descurar-se da qualidade do seu trabalho, traduzida na responsabilidade social de suas decisões, de modo a zelar sempre pela boa imagem da magistratura. Isso inclui manter a consciência de que pode utilizar-se das faculdades processuais para a realização do bem-estar social. Postergar a reparação do dano coletivo, pelo envio de recursos financeiros ao FAT, é delegar a solução efetiva ao Poder Executivo para um futuro incerto e sem os mesmos controles a que se submete a decisão judicial.

Segundo jurista português BOAVENTURA DE SOUSA SANTOS, "nós, integrantes do sistema de Justiça, não podemos resolver toda a injustiça, mas, se não fizermos a nossa cota-parte na redução da injustiça, de duas, uma: ou seremos ostracizados pela população ou então nos tornaremos uma instituição irrelevante" . $^{\text {. }}$

2 http://www.cnj.jus.br/index.php?option=com_content\&view=article\&id=21924\%3Asociologo-defende-responsabilidade-dos-tribunais-sobre-a-democracia\&catid=223\%3Acnj\&Itemid $=583$, acesso em 17/11/2012. 
E, ainda, vale lembrar a ideia de juiz-Hércules, uma metáfora utilizada por RONALD DWORKIN em suas obras sobre filosofia do direito para demonstrar as qualidades excepcionais, quase divinas, do juiz que toma a melhor decisão em cada caso ${ }^{3}$. O jusfilósofo descreve o juiz ideal como aquele dotado de sabedoria e paciência sobre-humanas --- capaz de desenvolver uma teoria política completa ao se deparar com um caso difícil, pois sua decisão não deve limitar-se a estar de acordo com o Direito, mas ser simultaneamente justificável do ponto de vista da moralidade política.

\section{Reversão para a comunidade lesada, no local do dano}

Em 23 de novembro de 2012, a Plenária da $1^{\text {a }}$ Semana Institucional do Tribunal Regional do Trabalho da $5^{\text {a }}$ Região aprovou ${ }^{4}$ tese deste autor, resumida na seguinte ementa: "DANO MORAL COLETIVO. INDENIZAÇÃO. REVERSÃO PREFERENCIAL PARA O LOCAL DO DANO. APLICAÇÃO DO ART. $2^{\circ}$ DA RES. $N^{\circ}$ 154/2012-CNJ NO PROCESSO DO TRABALHO. OFÍCIOS AO MPT E AO MP-BA".

A propositura do tema foi resultado de curiosa sequência de fatos.

Em dezembro de 2011, promovemos o I Congresso de Segurança Interinstitucional do Oeste da Bahia ${ }^{5}$. O evento culminou com a aprovação de 12 metas para a região, entre as quais a 9 , que, em síntese, apontava para a urgência de construção ou reparação de cadeias junto a delegacias da Polícia Civil. A corroborar a urgência dessa meta regional, recorde-se que o Brasil está sendo processado na Organização dos Estados Americanos por ter cadeias em péssimas condições de vida ${ }^{6}$ e o próprio Ministro da Justiça afirmou publicamente que preferiria morrer, a ser preso por longo período nas cadeias comuns do nosso País ${ }^{7}$.

Em março de 2012, homologuei acordo no curso de uma ação civil pública (ACP-0000410-02.2011.5.05.0651), inicialmente fixando compensação em pecúnia por dano moral coletivo, no montante de $\mathrm{R} \$ 205.000,00$, a ser revertida em prol daquela mesma meta: a construção ou a reforma de cadeias públicas, conforme o caso, em quatro municípios do oeste da Bahia (Bom Jesus da Lapa, Sítio do Mato, Santa Maria da Vitória e Correntina).

3 DWORKIN, Ronald. Levando os Direitos a Sério. São Paulo: Martins Fontes, 2002, pp. 164-203.

4 :http://www.trt5.jus.br/default.asp?pagina=noticiaSelecionada\&id_noticia=25209, acesso em 30/11/2012.

5 http://www.amatra5.org.br/noticias.asp?ID=205, acesso em 17/11/2012.

6 http://www.cidh.oas.org/Comunicados/Port/22.11port.htm e http://www.cidh.oas.org/countryrep/ brazil-port/Cap\%204\%20.htm, acesso em 30/11/2012.

7 http://ambito-juridico.jusbrasil.com.br/noticias/100187069/ministros-do-stf-criticam-sistema-prisional-brasileiro, acesso em 30/11/2012. 
Algum tempo depois e diante da dificuldade do Poder Executivo estadual em realizar as obras na celeridade e eficiência pretendidas, foi proposto pelo Juízo e obtido um novo acordo, em que a empresa, mesmo já tendo quitado sua obrigação de pagar fixada originalmente, aceitou submeter-se a novo e difícil encargo: realizar todas as quatro obras com seus próprios recursos e seguindo projetos e cronograma preparados pela Secretaria de Segurança Pública do Estado da Bahia para, em seguida, doar tais obras ao Estado.

Não houve a restituição, inicialmente, do dinheiro que a empresa já havia depositado à disposição do Juízo. Apenas no final da tarefa e após todas as fiscalizações, os valores originais poderão ser ressarcidos.

Por isso, com a aceitação em fazer o segundo acordo, infere-se que a empresa buscou demonstrar coerência com suas alegações de responsabilidade social para comunidades na região e em outros locais, espelhada na construção de escolas rurais que já havia entregue a algumas prefeituras.

As obras foram concluídas e está sob perícia para constatação do integral cumprimento do pacto. Há e houve constante fiscalização da Justiça criminal, do MP/BA, do MPT, da Secretaria de Segurança Pública do Estado da Bahia e das empresas que figuraram como parte na ação civil pública.

A proposição desse segundo pacto fundou-se na inabalável crença do Juízo de que as empresas e os indivíduos que compõem a sociedade têm significativo interesse no desenvolvimento socioeconômico de sua região, além, é claro, do próprio Estado (Ministério Público, Justiça do Trabalho, governo do estado, governos municipais) e das instituições sociais que acompanharam presencialmente as audiências (conselhos municipais de segurança, $\mathrm{OAB}$, etc.).

No caso específico, a crença foi confirmada no momento da anuência da empresa acionada em suportar novas e dificultosas obrigações, dificilmente aceitáveis para um olhar mais apressado.

O raciocínio contrário também é verdadeiro: saber da destinação de indenizações em pecúnia para fundos federais, a rechear cofres públicos distantes do local originário da lesão, é a causa da repulsa que muitos sentem ao se deparar com ações civis públicas.

Vale dizer, a prática favorece a conciliação nas ações civis públicas, porque atende aos seguintes anseios:

I) do Estado, em reparar o dano coletivo ou difuso por meio de tutela específica ou resultado prático equivalente (CPC, art. 461);

II) os trabalhadores lesados têm interesse no desenvolvimento socioeconômico de sua região e, muitas vezes, a solução não é trabalhista (por exemplo, para evitar o trabalho infantil, não basta só um ou vários cursos sobre o assunto, mas ajuda muito o apoio a projetos de educação, de alimentação escolar, de melhoria do transporte escolar, de doação de um carro exclusivo para vigilância em área escolar visada por traficantes de drogas (há precedente 
no Rio Grande do Sul), apoio a projetos de recuperação de menores infratores e/ou drogados --- que podem ser projetos da sociedade, do Poder Judiciário estadual, do Ministério Público estadual, dos poderes do município etc.); e

III) a empresa acusada tem interesse em reverter à sociedade recursos financeiros e humanos que passem a restaurar sua imagem, de forma que o Poder Judiciário atue não só para punir, mas, antes, para encontrar soluções práticas ao possível problema detectado.

Mesmo quando não há acordo, é interessante notar que, do ponto de vista processual, o Estado liberal do final do século XIX aplicava de forma neutra e indiferente as regras, por força da exacerbada importância que então se dava aos princípios da igualdade formal e da mais ampla liberdade individual. A legislação clássica objetivava precipuamente as tutelas meramente declaratórias e as ressarcitórias.

Já o direito processual contemporâneo permite ao magistrado a aplicação da modalidade processual mais adequada ao caso, respeitado o livre convencimento motivado.

Com efeito, os direitos fundamentais previstos na Constituição podem ser efetivados por intermédio do processo, se o jurisdicionado demandar em juízo. Por isso, cabe ao legislador criar normas processuais adequadas à satisfação desses direitos materiais. Contudo, é humanamente impossível prever todas as situações fáticas na lei, razão pela qual os códigos, não raramente, ou são omissos ou contêm as chamadas "cláusulas gerais", que são formulas mais genéricas a permitir ao intérprete (e, sobretudo, ao agente político) a adequação ao caso concreto.

Cabe, pois, ao juiz extrair a máxima efetividade das técnicas processuais, podendo, para tanto, lançar mão da tutela específica (ou determinar providências que assegurem o resultado prático equivalente ao do adimplemento da obrigação descumprida) para somente após optar por uma compensação pecuniária. É mais consentâneo ao preceito constitucional beneficiar sempre a região originária do dano coletivo, só deixando para última hipótese a destinação de recursos a algum fundo estadual ou, mais remotamente, federal.

Em outras palavras, visando ao máximo de efetividade, o juiz pode valorizar a tutela específica em prol do local do dano e evitar a destinação de recursos a fundos federais, como FAT, para que, com sua decisão, não termine por, incongruentemente, haurir ainda mais a economia de um local recém empobrecido pela ocorrência do dano coletivo.

Penso respeitosamente que a prática de fortalecer o FAT foi efetivamente útil em um período que esse fundo ainda era frágil, para que se estabilizasse. Entretanto, hoje tem fonte própria e suficiente de recursos. Note-se, por exemplo, que o patrimônio financeiro do FAT terminou $2011 \mathrm{em} R \$ 185,4$ 
bilhões e não há atualmente como o Codefat utilizar todo esse valor, por falta de $_{\text {projetos }}{ }^{2}$. Ademais, convém lembrar que a remessa de recursos para o FAT em ACP não atende a literalidade do art. 13 da LACP porque:

a) o Ministério Público não compõe o Conselho gestor desse Fundo; e, ainda mais importante,

b) seus recursos não se destinam a reparar o bem trabalhista coletivo/difuso lesado, mas, apenas, ao custeio do seguro-desemprego (um direito decorrente de lei - não corresponde a indenizar especificamente uma comunidade pelo dano moral coletivo sofrido); ao pagamento de abono do PIS (um direito decorrente de lei - não corresponde a indenizar especificamente uma comunidade pelo dano moral coletivo sofrido); e a subsidiar financiamentos do BNDES (o que não corresponde a indenizar especificamente uma comunidade pelo dano moral coletivo sofrido).

Em 4/7/2012 e nesse sentido, o Excelentíssimo Ministro JOÃO ORESTE DALAZEN, então Presidente do Tribunal Superior do Trabalho, concedeu medida liminar em ação cautelar em recurso de revista nos processos $n^{\text {os }}$ TST-CauInom-6981-06.2012.5.00.0000 e TST-CauInom-7001-94.2012.5.00.0000, porquanto, entre outros fundamentos, "como reconhecera, em princípio, a própria Juiza presidente da execução, não se afigura útil a exigência do depósito do expressivo valor da indenização dos danos morais coletivos. Por primeiro, porque retiraria do fluxo de caixa dos executados montante superior a um bilhão de reais. (...) E, finalmente, porque a retenção do referido valor não beneficiará a tutela das vítimas das doenças decorrentes da contaminação ambiental. Importante frisar que, nos termos da decisão exequenda, o valor reverter-se-á ao Fundo de Amparo ao Trabalhador - FAT, o que esvazia, por completo, a utilidade da abreviação do procedimento de apreensão patrimonial". Ressalto os ingentes e verdadeiramente hercúleos esforços da Excelentíssima Juíza do Trabalho MARIA INÊS TARGA nas inúmeras e constantes tentativas de conciliação, inclusive visando à reversão da quantia em prol da comunidade de onde originou o dano.

Destaco que a destinação de recursos à própria comunidade lesada é atividade jurisdicional típica, porque se trata do desdobramento da tarefa processual de decidir qual a tutela específica objeto da condenação. Por isso, a destinação de recursos à própria região lesada é tão relevante, inclusive do ponto de vista processual.

Nesse passo, destaco o auspicioso advento, em julho de 2012, da Resolução n 154 do CNJ. Entendo-a plenamente aplicável, por analogia, ao processo do trabalho.

8 (http://www.valor.com.br/brasil/2686822/uso-do-fat-para-qualificacao-caiu-46-no-ano-passado, acesso em 17/11/2012). 
É possível, pois, fomentar projetos multi-institucionais ${ }^{9}$, em parceria do Judiciário com outros órgãos do Estado (inclusive outros ramos da própria Justiça, CNJ etc.), visando, por exemplo, à inclusão de jovens no mercado de trabalho e ao tratamento de dependentes de drogas, o que poderá refletir na melhoria da segurança institucional da Justiça (seus usuários, servidores e juízes).

Tudo deve ser feito da forma mais científica e transparente, já que as decisões judiciais estão sob constante crivo do respectivo Tribunal, da Corregedoria Regional, da Corregedoria-Geral, do STF, do TST/STJ/STM, do CNJ, do CSJT, da imprensa, da OAB, do MPT, do MP Estadual, das partes e até mesmo dos próprios colegas. Além disso, deve nortear a ação do magistrado o hábito de levantar as necessidades sociais da região da Vara do Trabalho de forma científica (projetos, seminários etc.) e a atuação em parceria com outros agentes políticos e representantes de instituições democráticas da sociedade, para aumentar as garantias de lisura e de efetividade.

Alternativamente, é viável a destinação de recursos depositados à disposição do Juízo em decorrência de indenização moral coletiva ao FIA - Fundo da Infância e Adolescência ${ }^{10}$, porque se trata de um fundo municipal previsto no ECA, art. 88, IV, e administrado pelo Conselho dos Direitos da Criança e do Adolescente.

No município em que o FIA ainda não tiver sido criado, a simples determinação judicial desse depósito é um ótimo impulso para que o fundo passe

9 A ideia inspira-se na filosofia que embasa o programa TJC - Trabalho, Justiça e Cidadania, ao congregar diversas instituições da sociedade para alcançar um bem comum, com apoio da população e maior segurança dos usuários, servidores e membros da magistratura. Outro bom exemplo de sinergia dos órgãos do Estado vem da cidade do Rio de Janeiro, que sofria há muito tempo com a insegurança pública. Somente quando se intensificaram, simultaneamente, esforços dos diversos ramos dos Poderes municipais, do Estado membro e da União, inclusive do Poder Judiciário e diversas instituições civis e militares, obteve-se sucesso na pacificação e desenvolvimento socioeconômico de comunidades carentes como a Rocinha. E, mesmo após o primeiro período, mais crítico, iniciativas conjuntas permitiram o fornecimento e a continuidade de outros serviços públicos, não só aqueles ligados à segurança.

10 MODELO DE DESPACHO:

"1. Vistos etc.

2. DETERMINO, com fulcro nos arts. 227 da CRFB, 88, IV, do ECA, e $2^{\circ}$ da Res. 154/CNJ, este por analogia, que o montante depositado à disposição do Juízo (fls. $x$ ) seja dividido em três em partes iguais e CADA UMA DELAS SEJA DEPOSITADA em favor dos respectivos FIA - Fundo para a Infância e Adolescência dos municípios de

3. OFICIE-SE aos respectivos CMDCA - Conselhos Municipais dos Direitos da Criança e do Adolescente, a fim de que INFORMEM, EM 10 DIAS, o número da conta do FIA que deverá receber o depósito e para que PRESTEM CONTAS da utilização do recurso.

4. COMUNIQUE-SE o Ministério Público estadual junto a cada um dos municípios beneficiados, com cópia deste despacho (ao qual confiro FORÇA DE OFÍCIO), para que FISCALIZE como entender de direito. Registro por parte deste Juizo as homenagens de estilo.

5. INTIME-SE PESSOALMENTE o Ministério Público do Trabalho, autorizada a ciência desde logo pelo modo mais célere (fac-símile e telefone, certificando-se)." 
a existir e venha a melhorar a educação, a saúde e a segurança de crianças e adolescentes nas cidades e, por consequência, de suas famílias. Tudo de forma capilarizada, pela ação de diversos e tantos Juízes do Trabalho, espalhados no território nacional.

Nesse particular, registro que o Ministério Público estadual tem ajuizado ação civil pública para, se necessário, criar o FIA em cada um dos municípios beneficiados pela decisão trabalhista. Por isso, convém enviar cópia da decisão ao MP do respectivo estado. Isso significa também mais um ganho institucional: trabalhar em excelente parceria com o Ministério Público, seja para viabilizar a aplicação de recursos, seja para contar com sua fiscalização.

Há também os fundos estaduais. Nesse aspecto, reformulo pensamento anterior, em razão de uma indesejável centralização (e, note-se, delegada ao Poder Executivo), com possível aplicação em atividade distante do local do dano. Penso que os fundos estaduais não têm o mesmo mérito de um fundo municipal, bem mais próximo ao local da lesão, passível, inclusive, de uma fiscalização mais direta e efetiva por parte dos interessados. De toda forma, vale ressaltar que, para fomentar diretamente projetos laborais no âmbito de um estado membro, foi criado o Fundo estadual baiano de Promoção do Trabalho Decente - Funtrad (Lei estadual n ${ }^{\circ} 12.356 / 11$ ), que visa à captação, repasse e aplicação dos recursos para custear as políticas públicas destinadas a gerar mais e melhores empregos, com igualdade de oportunidades e de tratamento, além de combater os trabalhos infantil e escravo. O Funtrad ainda não foi plenamente implementado e somente o futuro mostrará, quanto a algum recurso que lhe seja destinado, se é eficaz em promover o desenvolvimento, e o quanto atenderá o local do dano.

Podem-se compensar pecuniariamente, ainda, diretamente, entidades cadastradas juntos aos MP, ao MPT e aos órgãos estaduais, como a CEAPA - Central de Apoio e Acompanhamento às Penas e Medidas Alternativas (http://www.seap. ba.gov.br/index.php/ceapa), consideradas oficialmente habilitadas para receberem doações advindas de processos judiciais. O Ministério Público do Trabalho também tem cadastrado entidades que considera aptas a receber incentivo.

Com isso, é viável enviar recursos para instituições que cuidam de deficientes, menores, drogados ${ }^{11}$ ou idosos, por exemplo. Há também hospitais públicos que se pode apoiar (com a doação direta de aparelhos, como para diálise, tomógrafos, mamógrafos, de ultrassom e outros, sobretudo em municípios distantes dos centros de tratamento). Nesse sentido, apoio da Justiça do Trabalho a projeto em município do oeste da Bahia gerou a construção de

11 Veja: www.onu.org.br/programa-da-onu-seguranca-com-cidadania-apoia-oficina-contra-drogas -para-jovens-na-bahia, acerca de ação multi-institucional do Programa Conjunto da ONU Segurança com Cidadania, em Lauro de Freitas, BA. 
maternidade modelo, atendendo a uma grande região que, antes, era atendida em grandes centros, como Salvador e Brasília ${ }^{12}$.

Além disso, sabemos que o papel das universidades e institutos científico-tecnológicos públicos vai além de fornecer mão de obra qualificada para o mercado de trabalho. As possibilidades de interação entre universidades e empresas se expandem na medida em que a Justiça eventualmente decida apoiar a geração de conhecimento, para que essas instituições e o país não se distanciem das tecnologias de ponta disponíveis nos países mais desenvolvidos, e em alguns casos, possa estar à frente na produção dessas tecnologias. Pode-se, por exemplo, consultar formalmente a Secretaria de Inovação do Ministério do Desenvolvimento, Indústria e Comércio Exterior, para indicação da instituição a receber a doação.

Essa mudança de rumos nas decisões judiciais é ainda mais urgente e oportuna quando se considera que, na seara trabalhista, há significativa tendência de aumento no número das ações civis públicas, cujo rol de legitimados é cada vez mais amplo ${ }^{13}$, graças à acertada nova redação dada pelo TST à sua OJSBDI2-130, que agora passa a rezar da seguinte maneira:

130. AÇÃO CIVIL PÚBLICA. COMPETÊNCIA. LOCAL DO DANO. LEI No 7.347/1985, ART. 2 ${ }^{\circ}$. CÓDIGO DE DEFESA DO CONSUMIDOR, ART. 93 (redação alterada na sessão do Tribunal Pleno realizada em 14.09.2012) - Res. 186/2012, DEJT divulgado em 25, 26 e 27.09.2012

I - A competência para a Ação Civil Pública fixa-se pela extensão do dano.

II - Em caso de dano de abrangência regional, que atinja cidades sujeitas à jurisdição de mais de uma Vara do Trabalho, a competência será de qualquer das varas das localidades atingidas, ainda que vinculadas a Tribunais Regionais do Trabalho distintos. III - Em caso de dano de abrangência suprarregional ou nacional, há competência concorrente para a Ação Civil Pública das varas do trabalho das sedes dos Tribunais Regionais do Trabalho.

IV - Estará prevento o juízo a que a primeira ação houver sido distribuída. (sem destaque no original)

Paralelamente, convém também destacar outra prática que tem se mostrado positiva. Ao se homologar um acordo em que uma ou várias entidades sejam beneficiadas com a destinação de recursos financeiros, pode-se impor às beneficiadas a simples assunção de um compromisso formal e expresso,

12 http://www.trt5.jus.br/default.asp?pagina=noticiaSelecionada\&id_noticia=29413, acesso em $12 / 9 / 2013$.

13 Arts. 8, III/CRFB, 513, “a"/CLT, 91/CDC, 5, V, “a” e "b", e 21/LACP; 129/CRFB e 83, III/LC-75/93; cancelamento da SUM-310/TST. 
antes do repasse de valores, de adotará práticas contra a corrupção. Trata-se de mais um óbice a eventuais desvios, ainda que de cunho ético, mas que tem sido bem recomendado por organismos internacionais e já adotado, no Brasil, por entidades respeitadas, como o Instituto Ayrton Senna.

\section{Considerações finais}

É muito bom ouvir de pessoas insuspeitas da comunidade um agradecimento à Justiça, principalmente por uma ação da qual tenhamos participado como profissionais. O reconhecimento espontâneo, verdadeiro, é parte importante da realização profissional de todo ser humano.

Imaginemos, pois, que os magistrados, advogados, promotores, procuradores, com a inestimável ajuda dos servidores e o interesse das partes, todos podemos contribuir localmente para que nossas regiões se tornem mais prósperas e pujantes. E, mais que isso, que se intensifiquem as ações entre as instituições republicanas e, dessas, com as organizações da sociedade e os cidadãos, a fim de se atingir maior e significativo desenvolvimento socioeconômico.

\section{Referências bibliográficas}

Carvalho F. Lapa. Mais de 800 partos em maternidade apoiada pela Justiça do Trabalho [Internet]. Tribunal Regional do Trabalho da 5a Região. 2013 [cited 2013 Sep 26]. Available from: http://www.trt5.jus.br/default.asp?pagina=noticiaSelecionada\&id_noticia=29413

Castro J. A explosão demográfica e a fome no mundo. Fome, um tema proibido. Rio de Janeiro: Ed. Civilização Brasileira; 2003.

Comissão Interamericana de Direitos Humanos- Organização dos Estados Americanos. AS CONDIÇÕES DE RECLUSÃO E TRATAMENTO NO SISTEMA PENITENCIARIO BRASILEIRO [Internet]. RELATORIO SOBRE A SITUACAO DOS DiREITOS HUMANOS NO BRASIL: Capítulo IV. [cited 2013 Sep 26]. Available from: http://www.cidh.oas.org/ countryrep/brazil-port/Cap 4 .htm

Comissão Interamericana de Direitos Humanos- Organização dos Estados Americanos. MECANISMOS INTERNACIONAIS DE PROTEÇÃO SE UNEM DIANTE DA GRAVE SITUAÇÃO DE TORTURA E SUPERLOTAÇÃO CARCERÁRIA NAS AMÉRICAS [Internet]. Comunicado de imprensa no22/11. 2011. Available from: http://www.cidh. oas.org/Comunicados/Port/22.11 port.htm

Críticas à gestão da segurança marcam debate sobre violência [Internet]. Folha de S. Paulo; 15/11/2012. [cited 2013 Sep 26]. Available from: http://www1.folha.uol.com.br/ cotidiano/1185985-criticas-a-gestao-da-seguranca-marcam-debate-sobre-violencia.shtml

Dworkin R. Levando os Direitos a Sério. São Paulo: Martins Fontes; 2002. p. 164-203.

Marshall TH. Cidadania, classe social e status. Rio de Janeiro: Zahar; 1967. 
Montenegro MC. Sociólogo defende responsabilidade dos tribunais sobre a democracia [Internet]. Portal Conselho Nacional de Justiça - CNJ. [cited 2013 Sep 26]. Available from: http://www.cnj.jus.br/index.php?option=com_content\&view=article\&id=21924 $\% 3$ Asociologo-defende-responsabilidade-dos-tribunais-sobre-a-democracia\&catid $=22$ $3 \% 3$ Acnj\&Itemid $=583$

Paula LAT. Acordo possibilita a construção de cadeias no interior da Bahia [Internet]. Tribunal Regional do Trabalho da 5ª Região- Itaberaba. [cited 2013 Sep 26]. Available from: http://www.trt5.jus.br/default.asp?pagina=noticiaSelecionada\&id_noticia=25209

Segurança interinstitucional é discutida no Oeste baiano [Internet]. Associação dos Magistrados da Justiça do Trabalho da 5a Região - Amatra5. 2011 [cited 2013 Sep 26]. Available from: http://www.amatra5.org.br/noticias.asp?ID=205

Zampier D. Ministros do STF criticam sistema prisional brasileiro [Internet]. Notícias JusBrasil. [cited 2013 Sep 26]. Available from: http://ambito-juridico.jusbrasil.com.br/ noticias/100187069/ministros-do-stf-criticam-sistema-prisional-brasileiro

Resumo: Tutela coletiva específica ou resultado prático equivalente: a indenização moral coletiva revertida para a própria comunidade lesada

Ao conhecer e julgar pedido de compensação por dano moral coletivo, incumbe ao Juiz do Trabatho conceder a tutela coletiva específica ou determinar providências que assegurem o resultado prático equivalente ao do adimplemento da obrigação descumprida (art. 461 do CPC c/c 50 LXXVIII, da CR). Dessa forma, facilita o acordo no processo; evita retirar recursos da área que já foi lesada (agravando a pobreza da região) para enviar a um fundo que não é destinado à reparação do dano moral coletivo; melhora da imagem do Poder Judiciário junto à população leiga, que passa a se projetar como mais moderna e efetivamente próxima aos problemas da sociedade; fortalece a consciência do Poder Judiciário desse aspecto de sua liberdade funcional e política (ou seja, decisória, não partidária). Presta atendimento direto aos lesados na região local do dano, como ocorre quando determina a realização de obras (aplicação do art. $2^{\circ}$ da Res. $n^{\circ} 154 / 2012-C N J$, inclusive no processo do trabalho, por analogia). É viável, ainda, que a indenização se dê por intermédio de aporte financeiro, preferencialmente a fundos municipais (como o FIA - Fundo da Infância e Adolescência). Trata-se de trabalho multi-institucional, em cooperação com outros poderes da República e ramos do Ministério Público, que maximiza o atendimento à finalidade do desenvolvimento socioeconômico, que incumbe ao Estado brasileiro. Cuida-se de um desdobramento da dimensão política do Poder Judiciário, que passa a ser ainda mais efetivo na construção de uma sociedade mais justa, desenvolvida e igualitária.

Palavras-chave: Ação civil pública; tutela coletiva específica.

Abstract: Specific collective tutelage or the equivalent practical result: collective moral reparation reverting to the injured community In understanding and judging an application for compensation for collective moral injury, it is incumbent upon the Labour Court to grant specific collective tutelage or to take the necessary measures to ensure a practical result equivalent to that which would have 
occurred had the obligation been fulfilled (Art. 461 of the CPC c/c 5, LXXVIII, of the CR). Thus, it facilitates agreement in the process; avoids removing resources from the injured area (aggravating poverty in the region) to send to a fund that is not destined for the reparation of the collective moral damage; it improves the image of the Judicial Power amongst the general population, causing it to appear more modern and in contact with the problems of society; it strengthens the Judicial Power's awareness of this aspect of its functional and political freedom (i.e. non-party, decision-making). It pays attention directly to the injured parties in the local region of damage, as occurs when it determines that works shall be carried out (application of Art. 2 of Res. No. 154/2012-CNJ, including in the work process by analogy). It is also viable that the reparation is made through financial support, preferably to municipal funds (such as the Childhood and Adolescent Fund). It is multi-institutional work, carried out in cooperation with other powers of the Republic and branches of the Prosecution Service, which maximizes consideration of the purpose of socioeconomic development, incumbent upon the Brazilian state. It involves an extension of the political dimension of the judicial power, which becomes even more effective in constructing a fairer, more developed and more egalitarian society.

Keywords: Public civil action; specific collective tutelage.

\section{Pedido de separatas:}

RINALDO GUEDES RAPASSI

rinaldorapassi@gmail.com 